the horse) there is no text, but a useful list of references is given; about a third of these are to papers or articles in Japanese.

The atlas will clearly be of considerable value in any department of veterinary anatomy, physiology or pathology, chiefly for reference when questions concerning the internal structure of the brain arise. It will often save search through scattered and not always readily accessible publications, and the use of a uniform terminology for all the brains is a great convenience. The information given is very limited, however. Much is somewhat elementary and, being based on sections, the picture is inevitably two-dimensional. The absence of stereotaxic coordinates or indeed of any adequate illustrations of the three-dimensional anatomy of these brains would make it difficult to use this atlas effectively in planning experimental neurosurgery.

To the neuroanatomist, the lack of cytoarchitectural information (except for the useful section on the horse diencephalon) is disappointing, and only the more obvious features of the fibre architecture are labelled. At the same time the atlas provides at least a preliminary and reliable survey, not available elsewhere, which will be a valuable guide to anyone beginning a study of these brains. For this purpose it is a virtue that it is not overloaded with the detailed and sometimes controversial identifications which make some neuroanatomical literature so tedious and unrewarding.

It is perhaps churlish to criticize for what is omitted when one realizes how much work is involved in preparing an atlas of only one brain. The author has dealt with six, all from common domestic animals, and one is grateful to have the information, whatever its limitations, systematically illustrated for the first time. $\quad$ F. GoLDBY

\section{POLYPEPTIDE HORMONES}

Pharmacology of Hormonal Polypeptides and Proteins Edited by Nathan Back, Luciano Martini and Rodolfo Paoletti. (Proceedings of an International Symposium held in Milan, Italy, September 14-16, 1967.) Pp. xi+ 660. (Plenum Press: New York, 1968.) \$27.50.

THIs book is a collection of seventy-six papers, including at least one on almost every known biologically active polypeptide. It is divided into eight sections, beginning logically with one on "Peptide and Protein Chemistry", which contains seven papers on techniques in peptide synthesis. In the second section, on posterior pituitary hormones, six groups of workers cover aspects of the storage, release and actions of the neurohypophysial hormones, and the structure-action relationships of their analogues. Most of the papers in this section, in contrast to the other ones, are of the review or essay type and, in my opinion, are the kinds of reports which should appear in a symposium of this sort.

The third section, on "Hypothalamic Neurohumoral Principles", perhaps more than any other, suffers from the lack of reported discussions. Most of the laboratories working on the nature of the hypothalamic releasing factors, or releasing hormones as Schally proposes we call them, were represented at the meeting. This is a very controversial field at present, and an observer would have been helped by critical discussions between the participants of, for example, evidence which leads some groups to consider luteinizing hormone releasing factor (LRF) to be a peptide and others to conclude that it is not.

The fourth section of the book contains fourteen papers dealing with the anterior pituitary hormones other than growth hormone. This protein appears briefly in the seventh section but was the subject of a separate symposium held in Milan immediately before this one. The reports cover all of the other anterior pituitary hormones in some aspect or other, and the topies range from puri- fication, through control of release, to actions at target organs.

Insulin and glucagon make up the fifth section, which is followed by two short sections, one on "Peptides Affecting Lipid Metabolism" and the other on growth hormone, the placental hormones and calcitonin. The book is completed by a section entitled "New Hormonal Peptides" containing twenty papers on miscellaneous active polypeptides including gastrointestinal hormones, the kinins, angiotensin and erythropoietin.

It is perhaps questionable whether the proceedings of large symposia, composed of communications rather than review articles, should be published at all, because most of the information they contain is published elsewhere and the literature is large enough already. Moreover, the length of time that they generally take to appear in print means that much of their contents is by then outdated. There is, of course, much in favour of the publication of the relatively small symposia in which not only are topies reviewed from different angles by an assortment of experts, but also discussions of their conclusions are reported.

The proceedings of the Milan polypeptide symposium, however, while falling in the category of collections of short communications, do justify their publication. The book is probably unique in its attempt to cover all known hormonal and quasihormonal polypeptides, and it provides, in the form of the bibliographies of its seventy-six constituent papers, a useful source of $r \in$ ference for researchers in all aspects of a vast field. The editors and publishers are to be congratulated on the speedy appearance of the volume in only nine months or so after the meeting, and the fact that this was made possible by a photographic process utilizing the original manuscripts does not detract from the finished article. The book is a collection of individual and separate papers, so that a lack of uniformity of typescript is neither important nor noticed.

B. T. Pickering

\section{NEUROSCIENCES RESEARCH}

Neurosciences Research Symposium Summaries

Vol. 2. (An Anthology from the Neurosciences Research Program Bulletin.) Edited by Francis O. Schmitt, Theodore Melnechuk, Gardner C. Quarton and George Adelman. Pp. xiii + 642. (Massachusetts Institute of Technology Press: Cambridge, Mass., and London, 1967.) $112 s$.

THE second anthology of reports from work sessions of the Neurosciences Research Program contains chapters on sleep (Nauta, Koella and Quarton), conditioning (Livingston), simple systems for the study of learning (Bullock), brain proteins (Schmitt and Davidson), biogenic amines (Kety and Samson), and the cerebellum (Bell and Dow). The programme, of course, owes its existence to Professor Schmitt; its value is clear, particularly when one thinks gloomily of the general standard of scientific meetings. It is quite a philanthropic organization-many British neurophysiologists benefit from free distribution of the reports of the work sessions as they are produced.

In general, each report contains reviews by a small number of experts of the progress in a field of the neurosciences including the discussions which developed at the meeting concerned. The reviews are followed by full bibliographies (usually 100 to 300 entries) with references both to works cited in the reviews and to further relevant publications. In this volume I have found all the chapters useful; all can be recommended as introductions to the recent literature in their chosen areas and have many of the features of full-scale monographs. The emphasis, however, is to some extent on agreement between the various participants at each session, so there is less idiosyncrasy than usual. The cheap but attractive method 